\title{
O PROGRAMA DE PESQUISA DE JOSÉ MARÍA CAGIGAL PARA O CAMPO DA EDUCAÇÃO FÍSICA
}

\author{
THE JOSÉ MARÍA CAGIGAL RESEARCH PROGRAM FOR THE FIELD \\ OF PHYSICAL EDUCATION
}

\section{EL PROGRAMA DE INVESTIGACIÓN DE JOSÉ MARÍA CAGIGAL PARA EL CAMPO DE LA EDUCACIÓN FÍSICA}

\author{
Isabel Cristina Martines*, Nataly de Carvalho Fugi**, \\ Juliano de Souza***
}

Palavras chave:

Ciência.

Epistemologia.

Corpo.

Movimento.

Keywords:

Science.

Epistemology.

Body.

Movement.

Palabras clave:

Ciencia.

Epistemología.

Cuerpo.

Movimiento.

\begin{abstract}
Resumo: Como parte de um esforço revisionista sobre a configuração teórica do campo da Educação Física, procuramos demarcar as especificidades do programa de pesquisa que José María Cagigal legou à área. Para dar conta desse objetivo, o manuscrito foi dividido em três seções. Na primeira delas, pretendemos oferecer um sumário do pensamento de Cagigal e identificar o lugar ocupado pela noção de cultura física em seu empreendimento. Na sequência, esboçamos alguns fundamentos que sustentam seu programa progressivo para a EF. Por fim, à maneira de síntese, sugerimos que seu programa de pesquisa não está em degenerescência e que algumas de suas noções não só são atuais como merecem ser retomadas.
\end{abstract}

Abstract: As part of a revisionist effort on the theoretical configuration of the Physical Education (PE) field, we sought to demarcate the specificities of the research program that José María Cagigal bequeathed to the area. To account for this goal, the manuscript was divided into three sections. In the first one, we intend to offer a summary of Cagigal's thinking and identify the place occupied by the notion of physical culture in his enterprise. Following, we outline some of the fundamentals that underpin your progressive program for PE. Finally, by way of synthesis, we will suggest that his research program is not in degeneracy and that some of his notions are not only current but deserve to be taken up again.

Resumen: Como parte de un esfuerzo revisionista sobre la configuración teórica del campo de la Educación Física (EF), procuramos demarcar las especificidades del programa de investigación que José María Cagigal legó el área. Para dar cuenta de ese objetivo, el manuscrito fue dividido en tres secciones. En la primera de ellas, pretendemos ofrecer un resumen del pensamiento de Cagigal e identificar el lugar ocupado por la noción de cultura física en su emprendimiento. A continuación, esbozamos algunos fundamentos que sostienen su programa progresivo para la EF. Por último, a la manera de síntesis, sugerimos que su programa de investigación no está en degeneración y que algunas de sus nociones no sólo son actuales como merecen ser retomadas.
*Universidade Federal do Paraná Setor Litoral. Matinhos, PR, Brasil. E-mail:

belmartines@hotmail.com

**Universidade Estadual de Maringá; Maringá, PR, Brasil. E-mail:

natikinha_cf@hotmail.com.

***Universidade Estadual de Maringá; Maringá, PR, Brasil. E-mail:

julianoedf@yahoo.com.br.

Recebido em: 08-05-2019 Aprovado em: 09-02-2020 Publicado em: 08-03-2020

(c) (i) (8) Licence 


\section{INTRODUÇÃO}

Desde a primeira metade do século $X X$, é possível visualizar, sobretudo no contexto europeu e norte-americano, a penetração e circulação de uma série de teorias no campo da Educação Física (EF) com o objetivo de propor avanços científicos à área (SOUZA, 2019a). Entre os países ocidentais, há que se destacar o peso de influências teóricas que irradiam na Europa a partir das décadas de 1940 e 1950 e passam a ser debatidas nos diversos espaços e eventos então existentes. No Brasil, onde a produção acadêmica na área toma corpo mais tardiamente, algumas dessas teorias, sobretudo as proposições que não estavam relacionadas à emergente agenda das chamadas teorias críticas da educação, foram duramente recusadas pela linha de pensamento que emerge no campo da EF a partir da década de 1980.

Assumindo os riscos inerentes à toda análise preliminar, podemos dizer que as críticas mais contundentes que receberam as propostas de delimitação de uma ciência própria pela EF foram estabelecidas a partir de três entendimentos fundamentais. Em primeiro lugar, apontou-se que aqueles pesquisadores que pleiteavam a demarcação de um estatuto científico para a EF, o faziam, em sua maioria, segundo os princípios da ciência positivista e privilegiavam em suas teorias a busca pela neutralidade científica, em detrimento a um posicionamento crítico à proposta. Em segundo lugar, se indicou que os modelos científicos para a EF se fundavam na ideia de supremacia da ciência em relação aos outros tipos de conhecimento necessários à atuação pedagógica desta disciplina. Em terceiro lugar, assinalou-se a urgência de combater proposições fundamentadas em abordagens médico-higienistas e biologicistas.

Sem desconsiderar a complexidade que envolve essas análises, e concordando com Taborda de Oliveira (2001, p. 114) quando argumenta que as críticas radicais no campo da EF foram dirigidas "aos modelos de ciência, mas raramente, quanto ao uso da ciência em si", é preciso mencionar o fato de que, ao longo das décadas seguintes, parte dessas teorias não só acabou entrando em uma espécie de processo de esquecimento/silenciamento, como parece ter experimentado uma menor expressão no país.

A partir dessa premissa acreditamos ser justificável, por dois aspectos principais, recolocar em debate programas de pesquisa que ainda permanecem pouco explorados ou "cientificamente testados" no status quo da EF brasileira. Primeiro, porque temos como hipótese que alguns deles podem ter sido rejeitados antes mesmo que tivessem seu grau de consistência submetido aos testes empíricos. Isso constituir-se-ia em um problema, afinal, como sustenta Lakatos (1979), se a racionalidade é uma questão de honestidade intelectual, só é possível ser racional quando estabelecemos as condições para aceitar ou rejeitar determinado referencial teórico. E, em segundo lugar, pela convicção de que alguém interessado em fazer avançar o conhecimento científico, nas mais diferentes áreas, deve conhecer a diversidade e amplitude de teorias já formuladas para então confrontá-las, testálas (em série), submetê-las ao crivo da prática, do experimento, da reflexão, da observação.

Frente a esse quadro teórico enunciado é que, ao longo do texto, objetivamos revisitar a obra de José María Cagigal Gutiérrez, demarcando as especificidades 
e contribuições de seu programa de pesquisa para a EF mundial. O interesse nesse tipo de investigação emerge, sobretudo, da necessidade de imputar revisões à configuração teórica do campo da EF à luz das dinâmicas epistemológicas que alavancaram seu desenvolvimento no mundo (SOUZA, 2019a, 2019b). Sem esse tipo de esforço revisionista de alcance global, muito dificilmente teremos um quadro epistemológico que nos permita localizar a rigor o desenvolvimento da EF brasileira no que de similar e diferente representa frente a outros cenários. Esse texto é uma contribuição nesse sentido, especialmente ao buscar compreender a obra de um dos principais autores da EF mundial a partir de um aporte da filosofia da ciência pouco utilizado, ao menos até onde sabemos, na área de EF no Brasil.

De modo a cumprir com esse objetivo, nos aprouve inicialmente realizar uma revisão teórica da obra de Cagigal ${ }^{1}$ com pretensões exegéticas. Paralelamente, realizamos também uma revisão exploratória acerca do que havia escrito sobre o autor nos idiomas português e espanhol. Para elaboração deste artigo, selecionamos intencionalmente aqueles textos e obras que buscavam apreender e avaliar o projeto cagigaliano em uma dimensão de totalidade. Nesse percurso, o programa metateórico de Lakatos para explicar os padrões de mudança e desenvolvimento científico, funcionou como uma espécie de guia para acionarmos a obra de Cagigal e visualizarmos os elementos estruturantes de seu programa de pesquisa.

O texto que segue está dividido em três partes. Na primeira delas, procuramos oferecer um sumário do pensamento de Cagigal e identificar o lugar ocupado pela noção de cultura física em seu empreendimento. Na sequência, esboçamos alguns fundamentos que sustentam seu programa progressivo para a EF. Por fim, à maneira de síntese, sugerimos que seu programa de pesquisa não está em degenerescência e que algumas de suas noções não só são atuais como merecem ser retomadas.

\section{A CONSTRUÇÃO DO ESQUEMA DE PENSAMENTO CAGIGALIANO E A CULTURA FÍSICA COMO BASE METAFILOSÓFICA}

O esforço de revisitar a obra de Cagigal nos coloca diante de uma trajetória intelectual que começou a ser construída no final dos anos 1950 e estendeu-se intensamente por quase três décadas, priorizando temáticas centrais aos estudos da EF e esporte. Para Olivera-Betrán (1997, n.p.), essa construção teórica perdurou "a lo largo de los años, traspasando el tempo [...] pero evolucionando". O espanhol José María Cagigal Gutiérrez nasceu em 1928 na cidade de Bilbao e faleceu em 1983 por ocorrência de um acidente aéreo. Viveu, portanto, a maioria de seus anos no período da ditadura franquista, embora essa questão político-social, até onde pudemos observar, não tenha se manifestado explicitamente ao longo de seus textos.

Cagigal recebeu uma intensa educação clássica, fundamentada no humanismo cristão, pois foi um "hombre educado en el seno de una familia cristiana de arraigados valores tradicionales, con una sólida formación clásica y una profunda fe", tendo

\footnotetext{
1 Para a elaboração do presente texto tivemos acesso à leitura de oito livros escritos por Cagigal, em versão digitalizada no idioma espanhol e com páginas não numeradas, que compuseram o corpus de análise da pesquisa. Optamos por apresentar as citações diretas mantendo a língua original, bem como não atribuir compulsoriamente números às páginas dos livros. No conjunto da produção cagigaliana, além dos títulos analisados (vide referências) destaca-se, também, o livro Los dos caminos del deporte (1975) que não tivemos acesso.
} 
pertencido à ordem religiosa Jesuítas de 1946 a 1961 (RAMIREZ-MACÍAS; PIEDRA DE LA CUADRA, 2011, p. 72). Sua cosmovisão foi notadamente influenciada por essa formação e assenta-se sobre uma filosofia antropocentrista da realidade, que coloca o homem ${ }^{2}$ no centro de seu universo mental, razão de todas as coisas na Terra e obra mestra de Deus.

Estudou na Sankt Georgen Graduate School of Philosophy and Theology, em Frankfurt, licenciou-se em Humanidades Clássicas pela Facultad Eclesiástica de Loyola e em Filosofia e Letras pela Universidad Eclesiástica de Oña. Mais tarde, também se diplomou em Psicologia Clínica pela Universidad Central - atualmente, Universidad Complutense - em Madrid. No ano de 1977, apresentou sua tese de Doutorado em Filosofia intitulada "Pur une theorie de l'education physique: une aproche du sport contemporain", na Universita Karlovy, em Praga, na qual o autor se propõe a demarcar o esporte contemporâneo como um programa de pesquisa de seu interesse (RIVERO-HERRAIZ; SÁNCHEZ-GARCÍA, 2018).

Além de uma ampla e diversa formação acadêmica em vários países, disfrutou de enorme prestígio internacional: organizou inúmeros eventos; foi fundador e codiretor de duas revistas essenciais na história esportiva espanhola - Citius, altius, fortius (1958-1976) e Deporte 2000 (1968-1977); recebeu diversas distinções, com destaque para o prêmio Philip Noel Baker Research Award, em 1972, considerado o Nobel do esporte; tornou-se embaixador na Academia Olímpica Internacional; atuou diretamente em doze organizações internacionais de EF e esporte existentes em sua época, exercendo participação consolidada no Conselho Internacional de Educação Física e Esporte da UNESCO, cargo para o qual foi reeleito sucessivamente até sua morte; e, considerado como seu maior feito, em 1966 criou o Instituto Nacional de Educação Física de Madrid, hoje denominado Facultad de Ciencias de la Actividad Física y del Deporte da Universidade Politécnica de Madrid e reconhecido como um centro de excelência internacional (RAMIREZ-MACÍAS; PIEDRA DE LA CUADRA, 2011; RIVERO-HERRAIZ; SÁNCHEZ-GARCÍA, 2018; INEF, 2019). No entendimento de Olivera-Betrán (1997), tão intensa inserção no âmbito político internacional foi condição imprescindível para a difusão do pensamento em torno de uma EF mais humana e pedagógica, alternativa ao empirismo e ao tecnologismo que prevalecia no contexto.

Olivera-Betrán (1997) aponta que a produção intelectual de Cagigal pode ser organizada em três fases: religiosa-pedagógica (1957 a 1966), filosófico-científica (1967 a 1977) e filosófico-sociológica (1977 a 1983). Essas etapas definem-se por mudanças notáveis em seu pensamento e são consideradas como "ciclos vitales distintos" (OLIVERA-BETRÁN, 1997, n.p.). Ainda conforme esse autor, também é possível notar o princípio da emergência de uma quarta fase de caráter filosóficoeducativa, iniciada em 1983 e interrompida neste mesmo ano em razão da morte de Cagigal.

Conforme Rivero-Herraiz; Sánchez-García (2018, p. 64), a teoria cagigaliana é transparente e à frente de seu tempo, pois trata-se de "un autor único que no pertence a ninguma generación, ni a ninguna escuela, que contribuye notablemente a un nuevo

2 Para Cagigal o termo homem é empregado como sinônimo de ser humano, embora note-se que ele utiliza mais acentuadamente o primeiro termo. 
modo de entender a interpretar al hombre". Sobre esse aspecto, Olivera-Betrán (1997, n.p.) considera que Cagigal foi "humanista, académico e inspirador de nuevas formas de entender el hecho desportivo", sendo pioneiro e influenciador decisivo na nova orientação da EF na Espanha, o que contribuiu para sua consolidação como campo de conhecimento científico e social. Ainda no entendimento do também espanhol Olivera-Betrán (1997, n.p.), Cagigal representa "el mejor y el más prolífico pensador contemporáneo que ha dado este país en el área del deporte y la educación física”.

Referindo-se especificamente a um artigo publicado por Cagigal no ano de 1974 na Revista Brasileira de Educação Física e Desportos, Taborda de Oliveira pondera que:

\begin{abstract}
[...] o enfoque do autor privilegia as Ciências Humanas, apesar de propor uma versão científica da Educação Física, a kinantropología [...]. Para esse autor espanhol, a ciência da Educação Física deve se basear na investigação cultural. Não é possível inferir desse trabalho qual a filiação epistemológica do autor. Destaco apenas que, apesar da prevalência das ciências naturais na conformação da Educação Física no período estudado [1954-1985], um periódico oficial [como a Revista...] dava largos espaços para as conjecturas humanistas de um dos principais intelectuais da Educação Física mundial, o qual não poderia ser enquadrado numa postura "naturalista", "biologicista" ou "positivista" (2001, p. 114, grifo nosso $\left.{ }^{3}\right)$.
\end{abstract}

De fato, a análise realizada sobre o conjunto de sua obra evidencia que o ser humano foi o verdadeiro interesse de todo seu trabalho teórico e educá-lo para que alcançasse uma dimensão mais transcendental, sem dúvida, seu maior objetivo de atuação. Corroborando essa constatação, Rivero-Herraiz; Sánchez-García (2018) afirmam que Cagigal buscou abordar a EF de forma educativa e profundamente humanista, fundamentando-se em bases científicas, na epistemologia, na psicopedagogia, na filosofia e na sociologia.

Dentre os temas investigados por Cagigal, destacam-se, sobretudo, o esporte, a EF escolar, o lazer, os Jogos Olímpicos, abrangendo discussões também voltadas às temáticas da legislação e agressividade. Oportuno salientar que tais assuntos, de uma maneira ou outra, sempre estiveram associados ao seu objeto de interesse maior, a saber, a educação integral do ser humano.

No entendimento de Cagigal (1979), a história dos programas educativos demonstra que a pedagogia praticada no ocidente, até o século XIX e, em alguns lugares, até o século $X X$, não conseguiu atingir a integralidade desejada para a educação, já que foi fortemente influenciada por interpretações dualistas do homem: desde as noções de corpo impuro e cárcere da alma imortal, derivadas do pensamento pré-socrático, passando pelas interpretações filosófico-morais cristãs que prevaleceram a partir dos séculos III e IV e previam docilizar o corpo pecaminoso para salvar o espírito, estendendo-se com a perspectiva cartesiana e a divisão entre res cogitans e res extensa, até a consolidação da fragmentação indivíduo-sociedade que emerge com o pensamento de Karl Marx, no século XVIII, e outros por ele influenciados.

3 Destacamos que o autor emprega a palavra "apesar" para expressar seu entendimento de que o texto de Cagigal aparece "como que para contradizer uma determinada leitura histórica que considera todo aquele rico debate, expresso no interior da Revista, apenas como consubstanciação de uma grande 'conspiração' mundial do capitalismo, do liberalismo e do positivismo" (TABORDA DE OLIVEIRA, 2001, p. 114). 
Na concepção antropológica de Cagigal, a dicotomia corpo-mente, enraizada nessas maneiras de compreender o ser humano, alimentou um vigoroso e nocivo princípio: a ideia de que uma dimensão seja separada da outra. Por um lado, o corpo é compreendido como origem de todo vício, pecado ou alienação - a depender do período histórico - e, por outro, o intelecto (espírito ou mente) é visto como aquilo que deve ser purificado, cultivado ou valorizado.

Para superar essa vazia e superficial polarização, "la educación debe atender a toda la persona", (CAGIGAL, 1972, n.p.) a partir de uma concepção integralizada, tendo em vista que só é possível ao ser humano conhecer (interagir e interpretar) o mundo que o rodeia a partir da entidade corporal: desde o começo da vida, todo o contato com o mundo é sensorial, físico. Nesse contexto, embora Cagigal reconheça que a expressão "el hombre corporal" supõe certa tautologia, assume que a emprega em um sentido uni-antropológico, pretendendo com ela, no fundo, reivindicar que o ser humano, por toda a sua existência, seguirá vivendo "no sólo en el cuerpo, sino con el cuerpo y, en alguna manera, desde el cuerpo y a través del cuerpo (CAGIGAL, 1979, n.p., grifos do original).

Para Cagigal (1979), os programas de educação tradicional privilegiaram em sua base, quase com caráter de exclusividade, o conceito denominado de cultura intelectual. ${ }^{4}$ Em sua visão, "la educación no puede reducirse a un cúmulo de enseñanzas - pecado intelectualista de nuestra tradición occidental" (CAGIGAL, 1972, n.p.) e, ao mesmo tempo, uma perspectiva que demonstra sinais empíricos evidentes de fracasso. Para o autor, a escola ter-se-ia convertido em um lugar de acumulação metódica de informação que supervaloriza o conhecimento do mundo exterior e a técnica. Sob sua ótica, seria necessário o abandono dessa lógica em prol de um novo e revigorado programa, fundamentado em uma interpretação integral do homem/corpo.

À luz da filosofia da ciência de Lakatos ${ }^{5}$, fica evidente que Cagigal (1979) interpreta o modelo educacional por ele criticado como um programa degenerativo. E, embora reconheça o surgimento de algumas renovações pedagógicas, acredita que essas não só são periféricas e complementares, como continuam falhando, fundamentalmente porque o âmago da matéria educativa permaneceu centrado na aquisição e na acumulação de "conhecimentos mentais".

Como alternativa a esse modelo, Cagigal ergueu um programa de pesquisa ${ }^{6}$ fundamentado na noção de cultura física, conceito que é amplamente defendido como

\footnotetext{
4 Sem deter-se na análise do conceito de cultura e sem entrar em distinções de escolas teóricas, Cagigal emprega o conceito de cultura intelectual, segundo ele, em sua mais simples exegese em que o termo "equivale simplesmente a cultivo del intelecto [...] del entendimiento, de la mente, de la inteligencia..., con toda la amplitude de horizonte que tem diversos términos acumulan" (CAGIGAL, 1979, n.p.).

5 Para Lakatos (1979), um programa de pesquisa se tornará bem-sucedido se a dinâmica dos seus elementos acarretar uma transferência progressiva de problemas e malsucedido se evidenciar uma transferência degenerativa. Silveira (1996), ao analisar essa teoria da ciência, aponta que um programa será considerado progressivo quando for capaz de prever fatos novos e alguma destas previsões apresentarem corroboração. Em contrapartida, será regressivo quando não for capaz de prever fatos novos ou quando os fatos previstos não forem corroborados.

6 Lakatos (1979) afirma que a ciência, de uma forma geral, pode ser considerada como um grande programa de pesquisa. Entretanto, o filósofo húngaro concentrou-se em descrever as características dos programas científicos de forma particular. Para ele, as mais importantes séries de teorias científicas se distinguem por uma continuidade que integram seus elementos. Esse processo de continuidade se desenvolve a partir de um programa de pesquisa que segue lógicas e dinâmicas próprias.
} 
núcleo duro e, de saída, não-refutável, ao longo de toda sua construção reflexiva. Nesse sentido, o conceito funcionou como uma espécie de metacompreensão, agindo com centralidade em todo o seu programa investigativo mais amplo e permitindo que outros programas de pesquisa, sucessivamente, derivassem dele e, inclusive, configurassem seus próprios núcleos. Em linhas gerais, a noção de cultura física em Cagigal (1979) significa duas coisas relacionadas e não-hierarquizadas: [1] que o ser humano conhece o mundo a partir de sua entidade corporal e [2] que vive, explora e apreende esse mesmo mundo pelo movimento. Nisso se constitui, portanto, "una cultura física contemporánea como fundamental aprendizaje al conocimiento de sí mismo, como cultivo de valores básicos de expresión personal y de relación social a través de las capacidades físicas" (CAGIGAL, 1979, n.p.).

$\mathrm{Na}$ esteira dessa compreensão metafilosófica identificamos outros dois assuntos com lugar privilegiado ao largo da produção intelectual cagigaliana e que aqui são compreendidos como programas de pesquisas paralelos, desenvolvidos com relativa independência: um deles mais voltado às dimensões pedagógicas da EF e à constituição dessa área como uma ciência; já, o outro, um programa que ocupou significativa parte de sua produção acadêmica e no qual abordou mais profundamente o esporte. É sobre a estrutura e especificidade do programa dedicado objetivamente à EF que trataremos na sequência, muito embora reconheçamos que o programa autônomo que o autor legou para o esporte, a partir da noção de homo deportivus, estabeleça muitas conexões e interfaces com a EF.

\section{UM PROGRAMA PROGRESSIVO E CIENTÍFICO PARA A EDUCAÇÃO FÍSICA}

Ao partir do pressuposto de que a cultura física deve se situar no centro de todo o processo educativo da pessoa, Cagigal apoia-se em duas grandes realidades antropológicas, o corpo (inerente e inalienável à pessoa) e o movimento (maneira pela qual o ser humano aprende, interage e se desenvolve em todos os aspectos) para definir a estruturação dos planos concretos da EF, compreendida como parte propedêutica desse sistema educativo mais amplo.

Conforme Cagigal (1981a, n.p.), o ser humano é "un ser corporal biológico hecho para moverse, necesitado vitalmente de movimiento". Para ele, todos os mecanismos cognitivos se apoiam na motricidade: se a linguagem e a conceituação, por exemplo, são consideradas "ações intelectuais" sobre objetos, em suas raízes repousa uma dimensão motriz permanente. Disso decorre a demarcação cagigaliana de que o objeto específico do campo científico da Educação Física é exatamente:

\footnotetext{
[...] el hombre que se mueve o capaz de moverse y en cuanto tal "hombre se-moviente", con todas las implicaciones a distintos niveles, desde los micro-somáticos (procesos bioquímicos, etc.) hasta los macro-somáticos e incluso psicológicos, los psico-sociales, sociológicos, sociopolíticos, con propia metodología y con un nada desdeñable "corpus" vigorosamente creciente (CAGIGAL, 1979, n.p., grifos nossos).
}

Amparado, entre outros, nas formulações de Jean Piaget, acreditava que somente graças ao movimento, o ser humano poderia multiplicar a possibilidade e a variedade dos estímulos que corporalmente recebe ao longo do processo de desenvolvimento. Cagigal traz à tona a afirmação que, em igualdade de condições, 
o cérebro estimulado por um corpo com amplas possibilidades de movimentos se estrutura vantajosamente - no que diz respeito à capacidade ou rendimento intelectual - em relação a outro limitado dessa possibilidade. Em seu entendimento, "la interacción cerebro-aparato locomotor es una garantía de desarrollo personal, e incluso de desarrollo específico de las funciones del pensar" (CAGIGAL, 1979, n.p.).

Além de fundamental para o pleno desenvolvimento do pensamento e de processos lógicos, o pesquisador, adicionalmente, conjectura que o ato motor é decisivo também nos processos de estruturação de outras capacidades, como a relação do ser humano consigo mesmo (percebendo seus limites e possibilidades), com o meio, a conformação dos esquemas espaço-temporais, a complexificação e a precisão da propriocepção - e, com isso, o enriquecimento das potencialidades operativas - a comunicação e a socialidade, a incorporação dos outros ao mundo próprio, a capacidade de integração, a afetividade.

Apesar da precisão do objeto estar bem delimitada sob seu ponto de vista, Cagigal (1972, n.p.) demostrava-se preocupado com o não-progresso da EF como campo científico, destacando que "importa ante todo haber delimitado este objeto y procurar depurar al máximo los métodos de investigación y, consecuentemente, los objetivos de las instituciones pedagógicas en las que se concreten las tareas de esta ciencia".

Percebemos ao longo da análise, corroborando as afirmações de OliveraBetrán (1997), que suas concepções teóricas foram se transformando em cada uma das fases, produzindo mudanças nos conceitos e definições em relação à EF. Entretanto, destacamos que a condição de "el hombre que se mueve" foi sendo, ininterruptamente ao longo de seu programa, apontado como o objeto central (ou específico) da EF, fazendo às vezes de núcleo irrefutável: a hipótese básica de que o ser humano somente existe em (com e desde) um corpo indivisível que aprende se movimentando não está em discussão.

Em sua primeira definição conceitual, Cagigal (1957), apresentava que "la educación física [...] ha de abarcar todo lo que pueda ser reconocido como educativo dentro de los ejercicios físicos. Por consiguiente, abraza tambíén el deporte" (s/p). Já em 1968, no artigo "La Educación Física, ¿ciencia?", delimitou a EF como "el arte, ciencia, sistema o técnicas de ayudar al individuo al desarrollo de sus facultades para el diálogo con la vida y consiguiente cumplimiento de su propio fin, con especial atención a su naturaleza y facultades físicas" (CAGIGAL, 1968, p. 9). Já no livro "Deporte, pedagogía y humanismo", sugere o termo "fisiopedagogía" como a ciência específica do educador físico, apresentando-a como uma entidade paralela e complementar à psicopedagogia. Em suas palavras:

[...] si la pedagogia es la ciência que ayuda al individuo al recto desarrollo de sus posibilidades y se introduce en el diálogo com el entorno, a fisiopedagogía seria la introducción a ese diálogo a través de la presencia física; entendiendo esta presencia o actitud como resultado manifestativo visible de todo lo individual (CAGIGAL, 1966, n.p.).

Em adição, posteriormente afirma que o campo científico da EF deveria compreender o homem como ser social em seu desenvolvimento espaço-temporal, inclinando-se, com esse diálogo, à concreta realidade física dos homens como 
exponente de suas próprias personalidades, afinal as expressões humanas, demonstradas através do dinamismo corporal, tratar-se-iam de vias centrais do movimento (CAGIGAL, 1972). Como nota-se, essa definição é muito parecida com a anterior, mas apresenta uma novidade importante: nela o movimento emerge como substrato base desse campo de conhecimento.

Alguns anos depois, Cagigal propõe uma ciência aplicada para a EF definindo-a como "el processo o sistema de ayudar al individuo en el correcto desarrollo de sus posibilidades personales y de relación social con especial atención a sur capacidades físicas de movimento y expressión" (1972, n.p., itálicos no original). Esse conceito apresenta variações substanciais em relação aos anteriores. Está relacionado a uma ciência do movimento humano, denominada pelo autor de "Kinantropología", da qual a EF seria a vertente pedagógica.

Em "Cultura intelectual y cultura física" (1979), especificamente no capítulo intitulado "Bases antropofilosóficas da Educação Física", possivelmente um de seus trabalhos mais importantes sobre a EF, considera-a como elemento estruturante da cultura física, devendo se fundamentar, por um lado, sobre o corpo (homem integral) e, por outro, sobre a realidade antropodinâmica do movimento físico.

Em "Deporte: espectáculo y acción" define que a EF "es toda tarea y la ciencia establecida alrededor del hecho de educar con el empleo del movimiento, el cuerpo, las capacidades psicomotrices. Dentro de todo ello se engloba el enfoque educativo del deporte" (CAGIGAL, 1981b, n.p.). Três teses se destacam nessa definição: a ideia de educar, a ideia do corpo e do movimento como bases dessa ação educativa e a inclusão do esporte educativo neste conceito. Também está presente, mais uma vez, a compreensão da EF como ciência.

Em seu último livro, "¡Oh Deporte! Anatomia de um gigante”, resume da seguinte maneira o problema da definição conceitual específica da EF:

[...] es una expresión referida a muy distintas áreas de la educación, que ha sufrido evoluciones y que ni hace cincuenta años ni ahora ha sido unívocamente entendida. Este es el primer problema que se plantea hablar de educación física en general. La misma disparidad de expresiones análogas que con más o menos fortuna han aparecido en las últimas décadas pretendiendo resolver el problema conceptual o intentando traspasar el área de trabajo de la educación física a otros que haceres educativos más de acuerdo con las nuevas corrientes, nos ofrece un reto lingüístico de enorme dimensión, y nos pone en evidencia una desmoralizadora falta de identidad de esta ciencia o subciencia pedagógica (CAGIGAL, 1981a, n.p.).

Mas é provavelmente em "Cultura intelectual y cultura física" que a denominação "Educação Física" é problematizada mais a rigor no corpo da produção teórica cagigaliana. Nesse livro, resultante de ensaios escritos pelo challenger espanhol desde 1975, há, em vários momentos, um esforço de demarcação daquilo que Cagigal considera serem as raízes da EF (o movimento e o corpo). Mais especificamente, o autor procura delimitar fins e objetivos para a EF sem, no entanto, procurar substitutos conceituais para a mesma:

Tampoco se asume en estas páginas el delicado tema de la oportunidad o inoportunidad de conservar en el momento presente la expresión "educación física" o de que ésta deba ser sustituida por "pedagogía físico-deportiva", "educación por el movimento", "psicomotricidad", "educación deportiva" 
o "ciencias del deporte" ... o tantas otras denominaciones más o menos sinónimas y más o menos adecuadas a últimas modas. Por el momento prefiero mantener la denominación tradicional, actualmente vigente en gran parte del mundo. Me hago eco, sin embargo, de la crisis inherente a tal concepto, crisis que en parte puede entrañar razones filológicas, pero que se deriva más bien de causas profundas, de transformaciones de la realidad pedagógica genérica, del enfoque de los sistemas y concepto mismo de educación, y que revierte em una indudable falta de identidad de la educación física como tal (CAGIGAL, 1979, n.p.).

Com a clareza de que os problemas de identidade da EF não se resolveriam por uma adequação meramente semântica, - mesmo porque em sua visão esses reportavam à própria hierarquização valorativa da cultura física na sociedade Cagigal era propositivo e não perdia do horizonte a busca por alternativas concretas. No texto "Deporte, pulso de nuestro tempo", por exemplo, se concentrou em refletir acerca de dois métodos de análises da EF como possível campo científico: um de natureza propriamente mais teórico-filosófica indicando unidades de pensamento que não estariam sujeitas à falseabilidade e que compunham a heurística negativa de seu programa; e outro, considerado por ele como mais realista, partia da premissa de investigar "el corpus aceptado culturalmente como totalidad de estudios y prácticas y especificado por el objeto considerado como propio de la educación física" (CAGIGAL, 1972 , n.p.), isto é, o homem em movimento ou o movimento humano como unidade constitutiva da heurística positiva do programa em tela.

Ainda em relação aos métodos de pesquisa abordados, Cagigal (1972) chamou atenção para algumas linhas de pesquisa claramente definidas no campo da EF: as ciências biológicas e os estudos pedagógicos, sendo esses domínios amparados na observação sistemática e em técnicas objetivas capazes de demarcar metodologias científicas específicas para a área. Nesse contexto, manifesta sua preocupação de que a cientificidade da EF fosse reconhecida apenas mediante determinadas ciências suportes a exemplo da medicina, fisiologia, anatomia, dentre outras. Em contrapartida, a ambição de seu programa era muito mais ampla e consistia na defesa de que a EF se desenvolvesse com autonomia, não mais na condição de "suma de las ciencias del hombre en la especial coyuntura del movimiento" (CAGIGAL, 1979, n.p.), mas como campo científico de conhecimento pedagogicamente aplicado que detêm um objeto próprio. Aqui um ponto de apoio importante ao programa da EF reflexiva (SOUZA, 2019), conforme iremos sugerir na sequência.

\section{CONSIDERAÇÕES FINAIS}

De acordo com Lakatos (1979), a história da ciência é uma história dos programas de pesquisa científica em concorrência e que tanto podem ser invisibilizados pelos rivais, quanto encerrados ou mesmo oportunamente recomeçados a depender dos critérios racionais eleitos pelos investigadores, segundo padrões de honestidade intelectual cada vez mais elevados. Por sinal, aspectos de determinados programas de pesquisa mais antigos podem ser herdados por programas de pesquisa mais recentes, sem necessariamente engendrarem uma perspectiva de continuidade ou de reprodução do anterior. Daí a importância de se (re)conhecer a rigor os programas de pesquisa em seu núcleo duro, cinturão protetor, heurísticas positiva e negativa, hipóteses auxiliares, de modo a fazer o conhecimento racionalmente avançar. 
Ao longo do manuscrito, ambicionamos remontar e evidenciar epistemologicamente a estrutura do programa de pesquisa investido por Cagigal no campo da EF. Nesse percurso, foi possível identificar não somente a constituição de um programa, mas de dois programas de pesquisa, um deles relacionado à especificidade científico-pedagógica da EF e outro ao esporte. Há que se mencionar também os esforços empreendidos por Cagigal no intuito de estruturar um programa amplo em educação que envolveria, inclusive, os demais. Em relação ao programa educacional, Cagigal realiza uma inversão teórica, de modo a situar no núcleo duro a noção de cultura física e não a de cultura intelectual. Relacionalmente ao programa em educação, por sua vez, emergiria o programa da EF como ciência - a Kinantropología - e, contido nesse, com centralidade na agenda investigativa do autor, o programa em esporte, por ele denominado de "El deporte na sociedade contemporânea".

Figura 1 - Fluxograma dos programas de pesquisa científica de Cagigal em Educação Física e em Esporte, tendo a noção de cultura física como núcleo duro de um programa geral em Educação

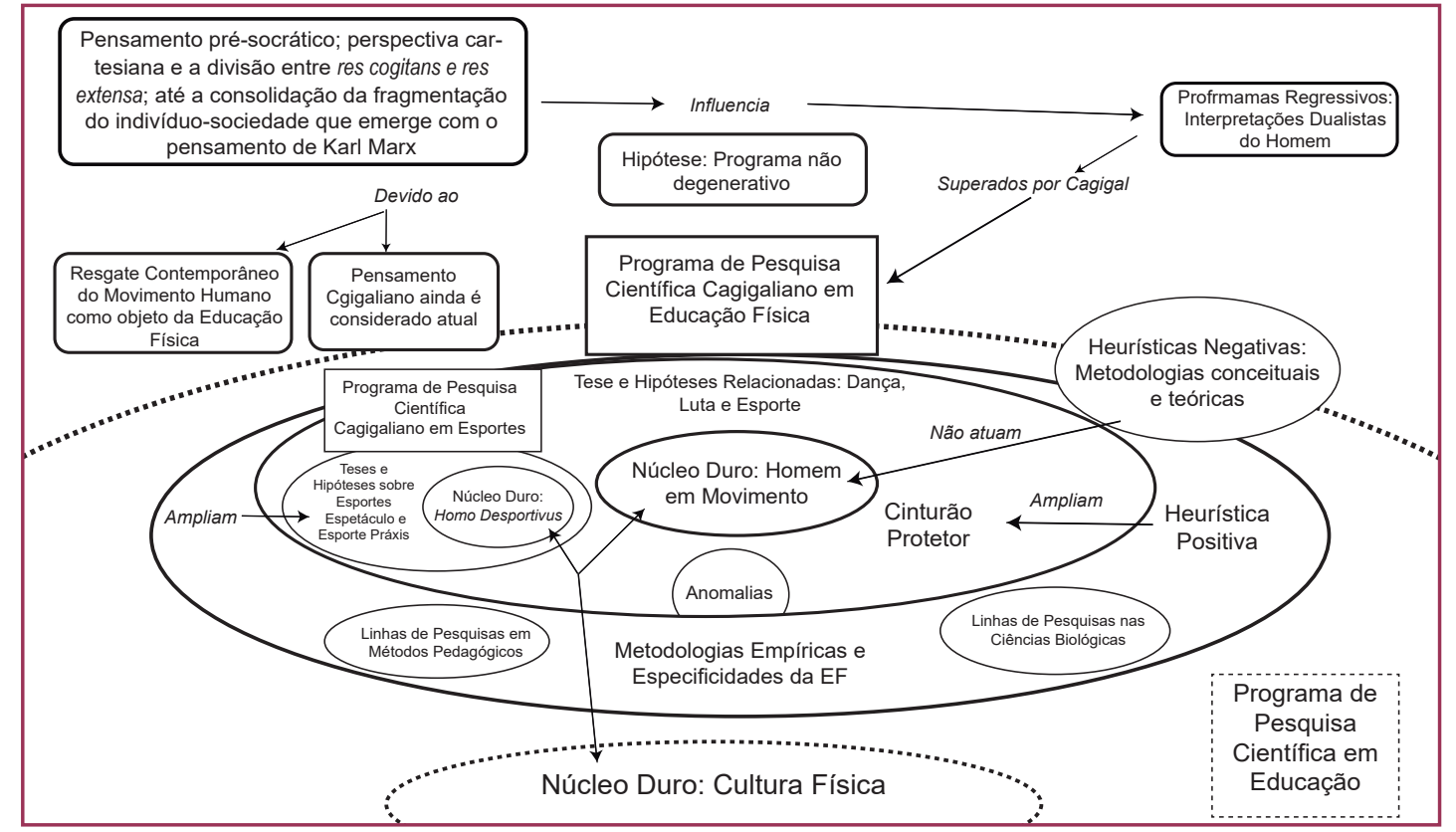

Fonte: Desenvolvido pelos autores.

Como sintetizado pelo fluxograma, no contexto do programa de pesquisa científica em EF atuam e orbitam as seguintes categorias programáticas: no núcleo duro e, de saída, não-refutável, repousa a noção de homem que se move; compondo a heurística negativa, as metodologias mais conceituais e teóricas; na heurística positiva, as metodologias mais empíricas que partem da realidade, bem como as metodologias específicas da EF; no cinturão protetor, por seu turno, se encontram as hipóteses auxiliares associadas ao tema da cultura física (o núcleo duro do programa de pesquisa científica em educação) e que têm no esporte o escopo geral das reflexões e proposições, seguido, de forma auxiliar, da luta e da dança.

Trata-se, conforme evidenciado, de um genuíno programa de pesquisa em EF legada não somente ao contexto espanhol e europeu, mas com potencial de transferência para outras realidades. No Brasil, por exemplo, o programa cagigaliano 
encontrou eco sistemático nas produções de Tubino (1992, 2004), muito embora ainda se façam necessários estudos mais consistentes para dimensionar a abrangência desse aporte teórico no país. De qualquer forma, pode-se dizer que, apesar do falecimento repentino de Cagigal aos 55 anos, o seu programa de pesquisa em EF já se encontrava bastante avançado e ficou para a posteridade.

Nesse sentido, é também possível sustentar que o programa de pesquisa de Cagigal para o campo da EF não se trata de um programa degenerativo, ao menos se tivermos em vista, conforme afirma Lakatos (1979), que o processo de substituição de programas de pesquisa estagnados por programas progressivos (revolução científica) não é um fenômeno relacionado à psicologia social como o é para Kuhn (1998). Ao invés disso, para rejeitar ou abandonar um programa é preciso que condições racionais sejam observadas: refutar uma teoria científica, empregando critérios não-científicos, não é um ato racional e a racionalidade, segundo expõe Lakatos (1979), está estritamente vinculada à ética do pesquisador.

Salvaguardados, portanto, por essa perspectiva filosófica que circunscreve e defende uma lógica pela qual a ciência se desenvolve e progride, é que aqui revisitamos a obra de José María Cagigal. Ademais, cabe reconhecer que, ao levar a rigor esse exercício, foi possível perceber a atualidade de algumas ideias do autor, tal como expressas em seu programa de pesquisa para o campo da EF internacional. Do ponto de vista de uma EF reflexiva (SOUZA, 2019b), a preocupação de Cagigal em articular os preceitos de uma teoria geral do "homem que se move" aos fundamentos de uma teoria da intervenção em EF, representa um esforço original de demarcar a especificidade científico-pedagógica da área, qual seja, a de satisfazer a necessidade de movência dos seres humanos em um contexto construído por eles próprios no intuito de limitar consideravelmente essa própria potencialidade.

Trata-se de um axioma importante ao programa da EF reflexiva (SOUZA, 2019b), mas que requer alguns reparos de natureza temporal, em especial porque a necessidade de movência dos seres humanos, além de ser cambiável em correspondência com a dinâmica macrossocial, não necessariamente apenas sofreria com as limitações estruturais e contextuais, sendo muitas vezes ela mesmo uma condição remodeladora das próprias estruturas. Se, por um lado, é possível concordar com Cagigal que o esporte e, mais amplamente, a EF seriam antídotos poderosos a essa "cultura da imovência" preponderante nas avançadas sociedades industriais, por outro lado, é necessário considerar que o sistema científico-pedagógico que a EF engendra, ao ser inventivamente apropriado pelos atores leigos, em especial no contexto da sociedade global de risco, tem ajudado a liberar o movimento humano ou o se-movimentar de seus compromissos com o contrato motor da primeira modernidade.

Essa é uma tese original soldada ao programa da EF reflexiva (SOUZA, 2019b) a partir de um exercício de interlocução crítica com o programa de pesquisa cagigaliano e, evidentemente, com outros programas investigativos na área (SOUZA, 2019a). Trata-se, vale a antecipação, de um esforço em avaliar os pontos de inflexão que a "cultura de movimento" passou na transição da modernização simples para a reflexiva, considerando o papel que foi e tem sido desempenhado pela área de EF em suas diferentes frentes de atuação nesse processo. Os significados, por seu 
turno, dessa dinâmica para os domínios da teoria geral e pedagógica da EF (SOUZA, 2019b), ainda estão em aberto e em desenvolvimento empírico-teórico no interior do referido programa de pesquisa.

À maneira de desfecho, ressalta-se a importância de conceber, pensar e organizar a atividade científica na área de EF a partir da metodologia dos programas de pesquisa de Lakatos (1979), afinal, tal proposta ao representar uma posição intermediária e sintética entre as lógicas interna e externa à ciência pode oferecer um aporte alternativo para repensar velhas tensões e dicotomias do campo da EF (SOUZA, 2019a). Vale lembrar que, ao longo deste artigo, nos propomos muito mais em operar com as noções de Lakatos (1979), para restaurar alguns dos sentidos e conexões estruturantes do programa de pesquisa de Cagigal, do que propriamente oferecer uma interpretação minuciosa dessa metateoria científica. Deste modo, uma exposição mais acurada de suas contribuições e limites para pensar o desenvolvimento científico na/da área de EF fica reservada a outras oportunidades.

\section{REFERÊNCIAS}

CAGIGAL, José Maria. Hombres y deporte. Madrid: Taurus, 1957.

CAGIGAL, José Maria. Deporte, pedagogía y humanismo. Madrid: Comité Olímpico Español, 1966.

CAGIGAL, José Maria. La Educación Física, ¿ciencia? Citius, Altius, Fortius, Madrid, n. 10, v. 1-2, p. 5-26, ene./jun. 1968.

CAGIGAL, José Maria. Deporte, pulso de nuestro tiempo. Madrid: Editora Nacional, Colección Cultura y Deporte, 1972.

CAGIGAL, José Maria. El deporte en la sociedad actual. Madrid: Prensa Española/ Magisterio Español, 1975.

CAGIGAL, José Maria. Deporte y agresión. Barcelona: Planeta, Difusión Cultural, 1976.

CAGIGAL, José Maria. Cultura intelectual y cultura física. Buenos Aires: Kapeluz, 1979.

CAGIGAL, José Maria. ¡Oh deporte! (Anatomía de un gigante). Valladolid: Miñón, 1981a. (Colección Kiné).

CAGIGAL, José Maria. Deporte: espectáculo y acción. Barcelona: Salvat, Temas Clave, $1981 \mathrm{~b}$.

INEF. Instituto Nacional de Educação Física de Madrid. Universidad Politécnica. Disponível em: https://www.inef.com/, Acesso em: 20 fev. 2019.

KUHN, Thomas Samuel. A estrutura das revoluções científicas. 5. ed. São Paulo: Perspectiva, 1998.

LAKATOS, Imre. O falseamento e a metodologia dos programas de pesquisa científica. In: LAKATOS, Imre; MUSGRAVE, Alan (orgs.). A crítica e o desenvolvimento do conhecimento. São Paulo: Cultrix: Editora da USP, 1979. p. 109-243. 
OLIVERA-BETRÁN, Javier. La educación física en el pensamiento de José María Cagigal (1928-1983): aportaciones y vigencia actual. Revista Digitales: Colección ICD: Investigación en Ciencias del Deporte, n. 16, 1997. Disponível em: https:// revistasdigitales.csd.gob.es/index.php//CD/article/view/175. Acesso em: 24 fev. 2020.

RAMÍREZ-MACÍAS, Gonzalo. PIEDRA DE LA CUADRA, Joaquín. Análisis de la obra de José María Cagigal en relación con el concepto de mujer y su inclusión en el deporte. Apunts: Educación Física y Deportes, n. 105, p. 67-72, 2011.

RIVERO-HERRAIZ, Antonio; SÁNCHEZ-GARCÍA, Raúl. José María Cagigal y su legado: una visión de la educación física desde las ciencias sociales. Revista da Alesde, v. 9, n. 1, p. 64-71, set. 2018.

SILVEIRA, Fernando Langue. A metodologia dos programas de pesquisa: a epistemologia de Imre Lakatos. Caderno Catarinense de Ensino de Física, v.13, n. 3, p. 219-230, dez. 1996.

SOUZA, Juliano de. Digressões acerca da ciência aplicada do movimento humano (ou sobre como podem prosperar revoluções simbólicas na área de Educação Física?). Revista Brasileira de Ciência e Movimento, v. 27, n. 4, p. 43-63, 2019 a.

SOUZA, Juliano de. Educação Física Reflexiva - problemas, hipóteses e programa de pesquisa. Movimento, v. 25, e25002,p. 1-15, jan./dez. 2019b.

TABORDA DE OLIVEIRA, Marcus Aurélio. A Revista Brasileira de Educação Física e Desportos (1968-1984) e a experiência cotidiana de professores da Rede Municipal de Ensino de Curitiba: entre a adesão e a resistência. 399f. Tese (Doutorado em História e Filosofia da Educação). São Paulo: PUC, 2001.

TUBINO, Manoel José Gomes. Esporte e cultura física. São Paulo: IBRASA, 1992.

TUBINO, Manoel José Gomes. Educação Física e esporte: da teoria pedagógica ao pressuposto do direito. In: LEBRE, Eunice; BENTO, Jorge Olímpio. (orgs.). Professor de Educação Física: ofício da profissão. Porto: Universidade do Porto, FCDEF, 2004. p. 235240. 